Dossiê - Para além do “ativismo judicial" e da “Judicialização da política” DOI: $10.5433 / 2176-6665.2016 \mathrm{v} 21 \mathrm{~N} 1 \mathrm{P} 13$

\title{
Tribunais, política e direito no Brasil. TendênCias E QUESTÕES PARA A CIÊNCIA POLÍTICA
}

\author{
Celly Cook Inatomi ${ }^{1}$ \\ E ANDREI KOERNER ${ }^{2}$
}

protagonismo de tribunais e de outras instituições judiciais,
as mudanças nos métodos de trabalho dos juristas e os processos de mobilização do direito são parte incontornável da política contemporânea. As mudanças foram acolhidas como o despertar do "terceiro gigante" ou como a emergência de uma nova era das instituições representativas, na qual se daria uma dinâmica positiva para o escopo e a efetividade dos direitos nas democracias constitucionais. Outros, mais céticos, apontaram os interesses corporativos de juristas, ou a sua associação com forças políticas e sociais como a base explicativa das mudanças. Mas, como têm apontado as pesquisas, o processo apresenta inegável variedade empírica, nos diversos contextos nacionais, no interior de cada Estado, em diferentes domínios, ao longo do tempo ou em função de configurações de forças postas em conjunturas específicas. Como resultado, as bases teóricas e metodológicas para a pesquisa de ciência política sobre os tribunais, os juristas e o direito permanecem dispersas, fluidas e contestadas, o que se apresenta de forma muito clara nos trabalhos na área sobre o nosso país.

1 Doutora em Ciência Política pela Universidade Estadual de Campinas (Unicamp), Brasil. celoca05@yahoo.com.br

2 Professor Doutor do Departamento de Ciência Política da Universidade Estadual de Campinas (Unicamp),Brasil. andreik@uol.com.br 
Este número da revista Mediações conta com artigos que contribuem neste domínio, seja com discussões de caráter teórico-metodológico seja com pesquisas empíricas sobre instituições, agentes e práticas judiciais no Brasil ou em perspectiva comparada. Não se trata de fazer aqui o balanço das discussões teóricas e metodológicas, que deram a orientação geral para a organização deste número e a seleção das propostas apresentadas. Remetemos a discussão aos nossos trabalhos ${ }^{3}$ e, no que segue, apresentamos os artigos publicados.

No artigo de abertura desta edição, "La oralidad. Nueva perspectiva de la justicia en Mexico", Angélica Cuéllar Vásquez nos mostra a confluência de fatores políticos e sociais, tais como o aumento da insegurança e da delinquência, especialmente do poder crescente do crime organizado desde os anos 1990, que possibilitaram a reforma do sistema judicial criminal no México. Ao apresentar as circunstâncias em que se deu a mudança do processo inquisitorial para o acusatório oral em seu país, a autora nos mostra como que tal mudança ajudou a criar uma percepção distinta de justiça entre as instituições e seus operadores. Segundo ela, a oralidade é o eixo central em que se dá essa mudança, guiando a interação entre todos os envolvidos no processo, tornando-o mais humanizado, garantista e preocupado com o respeito aos direitos humanos.

O segundo artigo, "Um canibal no banco dos réus? Entre o canibalismo e o vilipêndio a cadáver em um caso jurídico", Clark Mangabeira ajuda a quebrar com um dos pressupostos mais básicos da tese da judicialização da política, qual seja, a de que existiria uma forma única, lógica e objetiva do processo jurídico, que estaria sendo "invadido" por seu oposto, o processo político, ou vice-versa. Ao fazer uma análise empírica das narrativas jurídicas de acusação e de defesa num caso de canibalismo e vilipêndio a cadáver, o autor apresenta

3 Ver Inatomi, 2016a e 2016b; Maciel \& Koerner, 2002; Koerner, Inatomi \& Baratto, 2010; Koerner \& Inatomi, 2013; Koerner, 2016. 
as formas pelas quais pode ocorrer a construção de um crime no campo penal, tendo a dinâmica textual e a construção dos significados como eixos centrais de sua análise. Como mostra o autor, é possível observar que há uma clara "domesticação semântica" do que pode ou não pode ser falado e escrito na esfera jurídica, demonstrando que, para o convencimento tanto do juiz quanto dos jurados, dá-se a existência tanto de um trabalho lógico-jurídico quanto emotivo-moral que permeia de cima a baixo as discussões sobre justiça e moralidade.

Em artigo intitulado "'Era eu dizendo uma coisa e todo mundo dizendo outra': a constituição de vítima de 'abuso sexual infanto-juvenil' na justiça criminal", Irlena Maria Malheiros da Costa e Marcelle Jacinto da Silva demonstram, por sua vez, o "engessamento" ou a não permeabilidade do sistema judicial criminal à diversidade de elementos não materializáveis que são trazidos por casos de abuso sexual infanto-juvenil e que não são previstos pelo direito positivo ou pelas instituições públicas. Ao verificar como é que se forma a "vítima" na justiça criminal nos casos de abuso sexual infanto-juvenil, as autoras apresentam as inúmeras dificuldades para se conseguir provar a ocorrência dos abusos, conformando uma verdadeira "tecnicização" ou especialização na busca pela materialidade da violência sobre os corpos. O resultado é um processo que não olha para as complexidades e características que podem envolver o crime de abuso sexual infanto-juvenil, causando nas vítimas a sensação de desamparo e, por vezes, de violência, além da descrença nas instituições públicas, no arrependimento da denúncia e num alto número de casos sem resolução.

Em “Qual a classe, a cor e o gênero da Justiça? Reflexões sobre as (im)possibilidades de combate à violência doméstica contra as mulheres negras pelo Poder Judiciário brasileiro", Tatyane Guimarães Oliveira fala sobrea invisibilização da mulher negra junto às instituições judiciais, no âmbito da violência doméstica e familiar, que acaba 
por fortalecer o mito da democracia racial no Brasil. Ao propor uma reflexão sobre a atuação do Poder Judiciário na proteção de mulheres em situação de violência, considerando os marcadores sociais de raça, gênero e classe, a autora nos mostra que os princípios de atuação do Judiciário, como a neutralidade, a imparcialidade e a justiça, ao invés de constituírem uma perspectiva com maior capacidade de ser justa, têm sido mola propulsora para um vasto campo de violações de direitos e de uso estratégico da estrutura do Estado por grupos específicos para a manutenção de privilégios. As decisões dos tribunais brasileiros, em sua maioria marcadas pelo que a autora chamou de "cegueira da cor", não consideram o fator raça, não reconhecendo o racismo como crime, nem os seus desdobramentos possíveis em casos de violência contra a mulher negra, nos quais também pesam os recortes de gênero e de classe social.

Alessandra Teixeira e Eliane Alves da Silva, em "Conflitos fundiários urbanos e sistema de justiça: judicialização da política ou politização da justiça?", por seu turno, já questionam mais frontalmente os pressupostos trazidos pela tese da judicialização da política, muito embora o intuito do artigo não seja o de adentrar inteiramente nesse debate. Ao problematizar o papel do sistema judicial em conflitos fundiários urbanos, levando em conta as dicotomias que tem acompanhado o debate sobre a chamada “judicialização da política" e, mais especificamente, sobre a atuação dos tribunais em uma área historicamente marcada pela primazia do direito de propriedade, a intenção das autoras é a de reter a discussão naquilo que baliza a polêmica em torno da questão da judicialização: analisar os limites e os critérios para a efetivação de direitos pela via judicial numa democracia participativa. As autoras identificam a dimensão estratégica desempenhada pelos atores, mais propriamente pela Defensoria Pública, que não se dá através do controle judicial das políticas públicas propriamente dito. Ainda que sem sucesso 
pleno no âmbito da tutela jurisdicional, as autoras demonstram que a Defensoria Pública tem constituído um canal de interlocução das populações envolvidas nos conflitos com as instâncias encarregadas de formular e efetivar as políticas públicas, colocando uma miríade de questões de pesquisa que extrapolam aquelas postas pelas teses sobre a judicialização da política.

Em "As decisões judiciais e as políticas públicas sobre a educação no estado de São Paulo", Lígia Barros de Freitas nos apresenta resultados que questionam noções simplistas e dicotômicas sobre as relações entre direito e política, e a necessidade de considerar as complexas relações entre juízes, cidadãos e agentes públicos. Ao apresentar os resultados de um mapeamento das decisões judiciais sobre o direito à educação do Tribunal de Justiça de São Paulo, entre 1998 e 2013, ampliando as pesquisas que tratam da interação entre juízes e outros agentes na formulação e implantação de políticas públicas, a autora nos mostra que o Poder Judiciário tem constituído uma importante instituição na modelagem das decisões sobre as políticas públicas referentes ao direito à educação. Contudo, seu estudo também nos evidencia que houve mudança institucional do Judiciário pela maior aceitação da ação coletiva, bem como dos próprios atores que mobilizam o direito, como o Ministério Público e organizações civis, havendo uma interação entre esses fatores. Por meio da perspectiva do institucionalismo histórico, a autora pesa a participação dos atores envolvidos na questão do direito à educação, bem como a distribuição de poderes entre eles, para analisar os resultados políticos e jurídicos alcançados, mostrando indícios de mobilização do direito pelo Ministério Público, cuja busca pela realização de seus interesses e valores acaba por promover a efetivação do direito à educação e a interferência na formulação de públicas do Poder Executivo.

$\mathrm{Na}$ esteira de pesquisas sobre o papel desempenhado pelo Ministério Público, o artigo de Karen Artur, "Ministério Público 
do Trabalho: construção institucional, papel de agente e formação da agenda" vem elucidar, através de entrevistas realizadas com os próprios atores envolvidos, o conjunto de fatores que se mostram igualmente relevantes para explicar o papel de agente do Ministério Público do Trabalho, indo além das teses da judicialização da política e das relações sociais no Brasil. Ao tratar das mudanças organizacionais do Ministério Público do Trabalho relacionadas à concretização de seu papel de agente, a autora nos mostra que aquiloqueé vistonormalmente pela literatura como um voluntarismo político do Ministério Público pode remeter a uma conjunção de fatores: ao seu próprio desenho institucional posto na Constituição de 1988, no que ser agente não implica em ser substituto de uma sociedade dita hipossuficiente, mas sim ser responsável pelo desenvolvimento de ações estratégicas para que as novas atribuições constitucionais do Ministério Público se efetivem; e também à mobilização do direito por movimentos sociais e entidades sindicais, entendida aqui como um tipo de ação pela qual os interesses, valores de demandas dos atores sociais e organizações são traduzidos como uma questão de direitos constitutiva de seus discursos e estrategicamente direcionadas para também compor uma atuação coletiva do Ministério Público do Trabalho.

Fernanda da Silva Borges e Sandro Ballande Romanelli, em "Supremo espetáculo: aproximações sobre as imagens públicas do STF", trazem uma interessante análise sobre o papel da mídia na percepção da sociedade acerca da política e da justiça, demonstrando falhas importantes nas teses que falam numa crescentejudicialização da política no pós-1988, com especial protagonismo do Supremo Tribunal Federal. Ao fazer uma comparação entre informações veiculadas pela e sobre a Corte, os autores reconstituem uma possível imagem pública do STF. Além de mostrar que o protagonismo do Judiciário pode ser visto como uma situação tanto positiva quanto negativa para contexto constitucional, dependendo do respeito aos limites constitucionais 
e às regras do jogo democrático, o artigo demonstra que as tensões vividas entre as esferas políticas e jurídicas estão quase sempre atravessadas pelos discursos da mídia, provocando, assim, diferentes desdobramentos em relação à imagem pública do Judiciário. Assim, embora os autores atestem que não houve um aumento quantitativo de processos de cunho eminentemente político, eles verificam uma maior repercussão midiática dos casos que envolveram questões políticas, no que se deixa a impressão cada vez maior da interferência do STF em questões que deveriam ser solucionadas pelo Executivo e pelo Legislativo.

Raíssa Jeanine Nothaft, em "A judicialização da política como ferramenta dos partidos governistas (1995-2010)", caracteriza os possíveis e diferentes usos do Poder Judiciário pelos partidos políticos. Ao buscar compreender e comparar os casos em que a judicialização é utilizada pelos partidos de coalizão dos governos de Fernando Henrique Cardoso e de Luiz Inácio Lula da Silva, através do uso das Ações Diretas de Inconstitucionalidade na contestação de normas federais, a autora verifica que em ambos os governos os partidos governistas provocaram o STF, o que se enquadraria no que ela chama "judicialização como arbitragem de interesses em conflito". Os dados quantitativos indicam duas diferenças centrais nos usos das ADIs durante os governos FHC e Lula. A primeira delas foi a diminuição do uso do Judiciário pelos partidos em termos globais, e a outra foi o aumento no uso pelos partidos da coalizão de governo. Segundo a autora, os dados demonstram que o uso da "judicialização como instrumento de governo", que foi uma singularidade do governo Lula, esteve presente em poucas ADIs, no que se deveria somar outras variáveis explicativas para a diferença quantitativa entre o acesso aos tribunais pelas coalizões dos dois governos, como a quantidade de partidos da coalização do governo Lula e a possível resistência de um dos partidos da coalizão do governo FHC. 
Por fim, Igor Suzano Machado, Louise Siqueira Tavares, Gustavo Zenha Cordeiro e Bruno Oliveira, com "As associações de classe e o controle de constitucionalidade das leis via ADPFS" trazem um trabalho que busca olhar para a questão da judicialização da política não pelo viés comum pelo qual sempre é tratado, mas através de uma olhar "de baixo para cima", procurando analisar as razões e as características dos que mobilizam o direito nas esferas judiciais, bem como a polissemia do texto constitucional. Ao analisar as Arguições de Descumprimento Fundamental (ADPFs) propostas pelas associações de classe, o artigo analisa uma ação de controle de constitucionalidade que é utilizada em contingente bem menor que as Ações Diretas de Inconstitucionalidade, e que podem estar mais concentradas na defesa de direitos e fundamentalmente atreladas aos princípios constitucionais, que são normas de interpretação mais aberta e que podem ensejar entendimentos mais diversificados. Um dos principais resultados apontados pelos autores foi o uso estratégico da arena judicial, pelas associações de empresário contra o Poder Executivo federal, como um locus de ação política voltada para interesses corporativos travestidos de interesses gerais, na busca pela construção de uma hegemonia pela via judicial.

É com satisfação que apresentamos este número de Mediações, pois o conjunto dos artigos, publicados e submetidos à avaliação, mostra a consolidação das pesquisas sobre o sistema judicial e o direito em nosso país. Os trabalhos foram produzidos por pesquisadores, jovens doutores e doutorandos em programas de pós-graduação das áreas das ciências sociais e do direito em Universidades de diferentes regiões do país. Eles realizam pesquisas empíricas inéditas e demonstram criatividade e rigor na realização de suas pesquisas. Os seus referenciais teóricos e recursos metodológicos também são variados e bem utilizados. Trazem resultados inovadores, críticos, provocativos como deve ser a boa pesquisa acadêmica. 
Os artigos permitem prever que as pesquisas continuarão a se expandir, permitindo fortalecer a manter a reflexão teórica e análises empíricas que questionam discursos correntes simplificadores e preconceituosos sobre o tema. Agradecemos a Raquel Kritsch, Cleber Lopes e Pedro Lima, responsáveis pela revista e também aos amigos e colegas que participaram do esforço de preparação deste volume ao atuarem como pareceristas das propostas apresentadas.

\section{REFERÊNCIAS}

Inatomi, Celly C. A Atuação do Poder Judiciário nas Políticas de Erradicação do Trabalho Escravo Rural No Brasil Contemporâneo: Três Casos. Tese de Doutorado apresentada ao Departamento de Ciência Política do Instituto de Filosofia e Ciências Humanas da Universidade Estadual de Campinas sob orientação do Prof. Dr. Andrei Koerner. Campinas: Unicamp, 2016a.

"Abordagens teóricas na pesquisa empírica sobre o Poder Judiciário: diálogos, pontes, híbridos". In: Koerner, Andrei (org.). Política e Direito na Suprema Corte norte-americana: debates teóricos e estudos de caso. Ponta Grossa, São Paulo: EDUEPG \& EDUNESP, 2016b (no prelo).

Maciel, Débora A., Koerner, A. “Sentidos da Judicialização: duas análises”. Lua Nova. Revista de Cultura e Política, v.57, 2002, p.113 - 134.

Koerner, Andrei; Inatomi, Celly e Baratto, Márcia, 2010. Sobre o Judiciário e a Judicialização. Luís Eduardo Pereira da Motta e Maurício Mota (Eds.). O Estado Democrático de Direito em Questão. Ed. Campus-Elsevier, 2010, p. 149-180.

e Inatomi, Celly C. “O Supremo Tribunal Federal na Ordem Constitucional Pós-88: debates na ciência política". In: 60 Desafios do Direito Política, Democracia e Direito. São Paulo: Atlas, v.3, 2013, p. 77-90.

. Política e Direito na Suprema Corte norte-americana: debates teóricos e estudos de caso. Ponta Grossa, São Paulo: EDUEPG \& EDUNESP, 2016 (no prelo). 